\title{
A CALORIMETER FOR MEASURING FREE WATER CONTENT OF WET SNOW
}

\author{
by
}

Eizi AkItaya

Institute of Low Temperature Science, Hokkaido University, Sapporo, Japan 060

\section{ABSTRACT}

A new calorimeter was designed for measuring the free water content of wet snow, aiming at simplicity in mechanism and handling as well as high accuracy and speed in measurements. The mass of hot water to melt the sample and the mass of the mixture (snow sample and hot water) are measurable indoors with sufficient accuracy; therefore, in the field we need only two measurements of temperature $\left(\mathrm{T}_{1}\right.$ and $\left.\mathrm{T}_{2}\right)$; this calorimeter reduces the time of measurement of one snow sample to four or five minutes. Using artificially made wet snow, having a known value of free water content, 121 tests were conducted. Standard deviation of the error was $0.82 \%$

\section{INTRODUCTION}

Yosida (1959) designed a calorimeter for measuring the free water content of wet snow. Later Akitaya (1978) made an experimental apparatus of another type of calorimeter. This paper reports on further improvements made in the apparatus and measuring procedures. The free water content of wet snow is obtainable using this calorimeter, based on a melting calorimetric method using the following procedure:

Hot water $\left(\mathrm{T},{ }^{\circ} \mathrm{C}, \mathrm{M}\right.$, grams) and a sample of wet snow ( $M_{2}$ grams) are well mixed in a thermal insulating box so that the mixture attains $\mathrm{T}_{2}{ }^{\circ} \mathrm{C}$, the equilibrium temperature. If heat loss is neglected in this procedure, it follows that

$$
\mathrm{cM}_{1}\left(\mathrm{~T}_{1}-\mathrm{T}_{2}\right)=\mathrm{cM}_{2} \mathrm{~T}_{2}+\mathrm{LI}
$$

where $c$ is the specific heat of water $(4.18 \mathrm{~J} / \mathrm{gK})$ and $\mathrm{L}$ is the latent heat of melting of ice $(333.6 \mathrm{~J} / \mathrm{g})$. W (\%), the free water content of the snow, is expressed by

$$
\mathrm{W}=\left(1-\frac{\mathrm{I}}{\mathrm{M}_{2}}\right) \times 100=100-\frac{1.25\left(\mathrm{M}_{1}\left(\mathrm{~T}_{1}-\mathrm{T}_{2}\right)-\mathrm{M}_{2} \mathrm{~T}_{2}\right)}{\mathrm{M}_{2}} \text {. }
$$

\section{APPARATUS AND OPERATIONAL TECHNIQUE}

The new calorimeter has two spaces $W$ and $S$ in which a polythene tube $0.02 \mathrm{~mm}$ thick is embedded. The part of the tube in $\mathrm{W}$ contains hot water, and the other

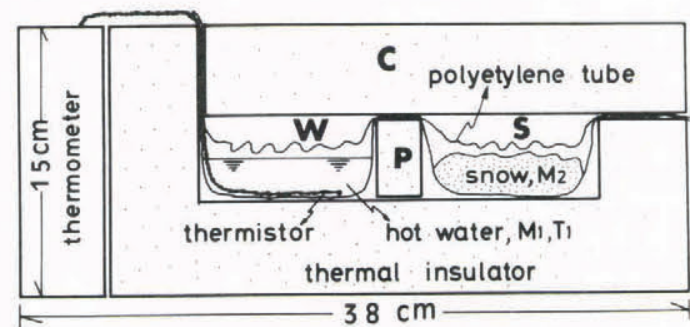

Fig.1. Schema of the calorimeter. Thermal insulator is made from hard plastic foam (density: $0.037 \mathrm{~g} / \mathrm{cm}^{3}$ ). part contains the snow sample. The two parts are divided by a movable parting strip P (Figure 1). Temperatures $T_{1}$ and $T_{2}$ are measured by a thermister with small heat capacity and high response, accurate to $0.1^{\circ} \mathrm{C}$. Mass measurements $\left(\mathrm{M}_{1}\right.$ and $\mathrm{M}_{1}+$ $\mathrm{M}_{2}$ ) are conducted indoors using a balance accurate to 0.1 gram; in the field it is difficult to avoid wind influences on the sample, and especially to prevent it from being heated and cooled from outside. In using the apparatus:

(1) Two plastic bottles A $\left(110 \mathrm{~cm}^{3}\right.$, filled with hot water) and B (250 $\mathrm{cm}^{3}$, empty) are weighed indoors and brought to the observation site in the field.

(2) Hot water is put into one half of the tube, which is inserted into space $\mathrm{W}$ with the thermister in it.

(3) A sample of wet snow ( 30 to $50 \mathrm{~g}$ ) is put into the other half of the tube and inserted into $\mathrm{S}$. The tube is covered with $C$ and the temperature of hot water $T_{1}$ is read on the thermometer while shaking the apparatus.

(4) After reading of $T$, the parting strip $P$ is removed: the snow sample and hot water mix, resulting in a rapid drop in temperature of the water. Equilibrium temperature $T_{2}$ of the mixture is read while shaking the apparatus for about one minute.

(5) The mixture $\left(M_{1}+M_{2}\right)$ is put in bottle $B$ with the tube after the measurement of its temperature $T_{2}$. Two bottles A (empty) and B are carried back indoors to weigh them so that masses $M_{1}$ and $M_{2}$ are measured accurately.

\section{CALIBRATION OF THE APPARATUS}

Calibration of free water content was examined by this apparatus in a cold room at $0^{\circ} \mathrm{C} \pm 1{ }^{\circ} \mathrm{C}$, as follows. An adequate amount of the dry snow at $0^{\circ} \mathrm{C}$ was put into the tube, and immediately a suitable amount of water at $0^{\circ} \mathrm{C}$ was added. The snow sample in the tube thus had acquired a known value of free water content Wa. Measured value of free water content W, calculated by Equation (2), was compared with the known value Wa. The standard deviation of the error (W - Wa) was found to be $0.82 \%$ for 121 samples with range of free water content from $0 \%$ to $45 \%$.

\section{DISCUSSION OF ERROR}

In equations (1) and (2) heat loss from the calorimeter and heat capacity of the tube are neglected. When the two quantities are to be considered, the following equation holds:

$$
\left(\mathrm{cM}_{1}+\mathrm{c}^{\prime} \mathrm{m}\right)\left(\mathrm{T}_{1}-\mathrm{T}_{2}\right)=\mathrm{T}_{2}\left(\mathrm{cM}_{2}+\mathrm{c}^{\prime} \mathrm{m}\right)+\mathrm{LI}+\mathrm{Q}
$$

where $c^{\prime}$ is the specific heat of the tube (about $2 J / g K$ ), $\mathrm{m}$ is the mass of it contacting with the hot water or the snow sample directly (about $0.4 \mathrm{~g}$ ), and $\mathrm{Q}$ is the heat loss in Jules. From Equation (3) the corrected value of free water content $\mathrm{W}_{0} \%$ is given by

$\mathrm{W}_{0}=100-\frac{1.25\left(\mathrm{M}_{1}\left(\mathrm{~T}_{1}-\mathrm{T}_{2}\right)-\mathrm{M}_{2} \mathrm{~T}_{2}\right)}{\mathrm{M}_{2}}+\frac{0.48 \mathrm{~T}_{2}-0.24 \mathrm{~T}_{1}+0.3 \mathrm{Q}}{\mathrm{M}_{2}}$ 


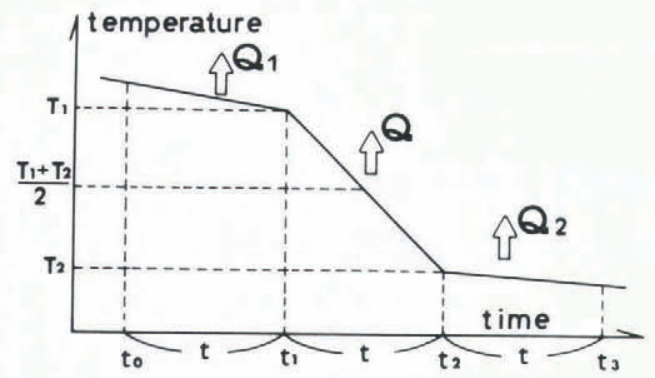

Fig.2. Schematic diagram of the heat loss, Q. $\mathrm{Q}$ is a function of $\left[\frac{T_{1}+T_{2}}{2}\right]$ since $Q_{1}\left(Q_{2}\right)$ is obtained empirically as a function of $\mathrm{T}_{1}\left(\mathrm{~T}_{2}\right)$.

Figure 2 shows a schematic diagram representing heat loss through the calorimeter, where $t_{1}$ and $t_{2}$ are the measuring times of temperatures $T_{1}$ and $T_{2}$, respectively: $Q_{1}$ and $Q_{2}$ are resultant heat losses during time $t$, obtained from the temperature drops. Values of $Q_{1}$ and $\mathrm{Q}_{2}$ were measured against the several ranges of water temperature $\mathrm{T}$ at the air temperature $0^{\circ} \mathrm{C}$ and the following empirical equation was obtained approximately:

$$
\mathrm{Q}_{1,2}=4 \mathrm{~T}(\mathrm{~J} / \mathrm{min}) \text {. }
$$

The heat loss $Q$ during mixing time $t=t_{2}-t_{1}$ (one minute) in Figure 2 can be given by substituting the mean temperature, $\left(\mathrm{T}_{1}+\mathrm{T}_{2}\right) / 2$ into $\mathrm{T}$ of Equation (5):

$$
\mathrm{Q}=2\left(\mathrm{~T}_{1}+\mathrm{T}_{2}\right)(\mathrm{J} / \mathrm{min})
$$

Substituting Equation (6) into (4), we obtain

$$
\mathrm{W}_{0}=\mathrm{W}+\Delta \mathrm{W}
$$

where $\mathrm{W}_{0}$ is the corrected value, $\mathrm{W}$ is the uncorrected value and

$$
\Delta \mathrm{W}=\frac{0.4 \mathrm{~T}_{1}+1.1 \mathrm{~T}_{2}}{\mathrm{M}_{2}}(\%)
$$

The equation shows that $\Delta W$ is inversely proportional to $M_{2}$ and increases with $T_{1}$. The error $\Delta W$ can be calculated against $T_{1}$ and $M_{2}$, because the almost constant mass of hot water $\mathrm{M}_{1}$ is prepared (about $110 \mathrm{~g}$ ) and $T_{2}$ is the function of $T_{1}, M_{1}$ and $M_{2}$. When the free water content is $0 \%$, equilibrium temperature $T_{2}$ is given by substituting $I=M_{2}$ in Equation (1) and Equation (8) becomes

$$
\Delta W=\frac{165 \mathrm{~T}_{1}+0.4 \mathrm{~T}_{1} \mathrm{M}_{2}-87.7 \mathrm{M}_{2}}{\mathrm{M}_{2}\left(110+\mathrm{M}_{2}\right)}
$$

Figure 3 shows the error of free water content $\Delta W$ due to Equation (2) in which the heat loss and heat capacity of the tube are neglected, and also the guideline of $M_{2}$

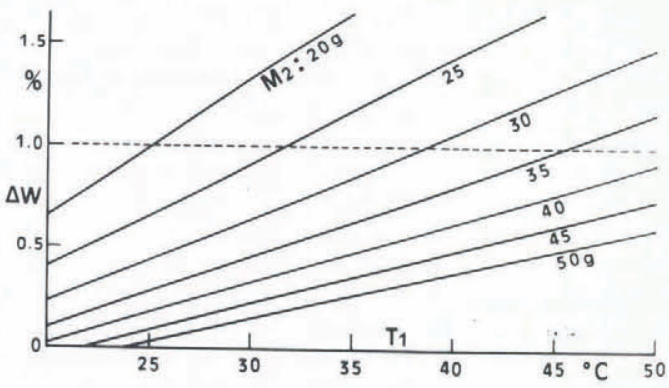

Fig.3. The guideline of $M_{2}$ against $T_{1} . M_{2}$; the mass of a snow sample, $\mathrm{T}_{1}$; the temperature of hot water. against $\mathrm{T}_{1}$. Allowing for $1 \%$ of the error, the appropriate value of $M_{2}$ is given against $T$, from this figure. For instance, if $M_{1}=110 \mathrm{~g}$, then $M_{2}{ }^{1}=40 \mathrm{gram}$ at $\mathrm{T}_{1}=50^{\circ} \mathrm{C}$ and $\mathrm{M}_{2}=35$ gram at $\mathrm{T}_{1}=40^{\circ} \mathrm{C}$.

\section{REFERENCES}

Akitaya E 1978 Measurements of free water content of snow by calorimetric method. Low Temperature Science. A, 36: $103-111$

Yosida Z 1959 A calorimeter for measuring the free water content of wet snow. Low Temperature Science, A, 18: 17-28 